\title{
La imposible carrera para adelantarse al futuro
}

\author{
Abraham SANTIBÁÑNEZ*
}

No hay manera de anticiparse con certeza absoluta al veredicto de la historia. Hoy nos parece que el 2006 puede figurar en el futuro como el año en que se consolidó el "blog", destinado, según parece, a generar una nueva cultura de participación. Pero ¿será realmente así?

Algunas de las historias en que los bloggeros son los protagonistas hablan de un cambio radical en el ejercicio informativo. Se ha terminado, se dice, la dictadura de los periodistas, que tenían el poder de definir lo que es noticia y su importancia. Igualmente, esta nueva era, profundamente más democrática, estaría marcada por la capacidad de acceder a los mismos lugares reservados hasta ahora exclusivamente para los periodistas o, mejor aun, a aquellos a los cuales no llegan habitualmente. De este modo, hemos sido testigos de acontecimientos dramáticos, nunca antes mostrados "en vivo y en directo", desde el tsunami de Indonesia hasta las explosiones en el tren subterráneo de Londres, donde se captaron testimonios de la evacuación de los pasajeros en teléfonos celulares provistos de cámaras fotográficas. Cámaras caseras han servido también para corroborar denuncias de todo tipo que, de otro modo, difícilmente habrían sido acogidas por la prensa y que probablemente se habrían eternizado en los tribunales.

Es evidente que el avance tecnológico nos beneficia. Pero también nos obliga a pensar en la otra cara de la medalla: denuncias falsas, alteración deliberada de imágenes, intromisiones no justificadas en la intimidad de las personas... en fin: asistimos al surgimiento de un nuevo paradigma: "noticias" que no son tales pero que se difunden por el mundo entero y opiniones que carecen de todo fundamento, como las que abrieron camino a la fama en Chile a los "opinólogos".

Como recuerda el autor argentino Julio Orione ${ }^{1}$, "el periodismo on-line es una nueva manera de hacer periodismo, diferente de las demás por las características peculiares del soporte". Pero, aclara, ello no significa que se abran indiscriminadamente las puertas y que "el manejo de la información... se convierta en tierra de nadie o, peor aún, en una cuestión exclusivamente de marketing". Según este autor, "para hacer periodismo on-line, hay que ser periodista, es necesario saber hacer periodismo".

Lograr una equilibrada visión de los aspectos positivos y los negativos de esta etapa de definiciones y descubrimientos es una tarea pendiente. En rigor, no ayudan los entusiasmos ni los rechazos sin matices.

\section{Gutenberg descartado}

Tal vez la historia de Gutenberg, en una versión "actualizada", puede ayudar a entender las complejidades del desafío. La narró aquí en Chile Juan Antonio Giner, de la Universidad de Navarra, y así fue recogida en mi texto "Introducción al Periodismo"2:

A mediados del siglo XV apareció en Maguncia un artesano que aseguraba haber inventado un extraño artefacto capaz de producir copias múltiples en páginas impresas similares a las de un manuscrito. La noticia llegó a oídos del gobernador del Estado quien, movido por el espíritu renacentista e innovador de la época, reunió a un

\footnotetext{
*Académico de la Universidad Diego Portales. Integrante del Consejo de Etica de los Medios y del Tribunal de Etica y Disciplina del Colegio de Periodistas.

${ }^{1}$ ORIONE, Julio. Introducción al Periodismo. Ediciones La Flor. Buenos Aires. 2006.

${ }^{2}$ SANTIBÁÑEZ, Abraham. Introducción al Periodismo. Editorial Los Andes. Santiago. 1994.
} 
grupo compuesto por académicos y hombres de negocios para que analizaran la trascendencia y el impacto que pudiera tener aquel prodigioso descubrimiento sobre la cultura y la economía locales.

A tal efecto, pocos días después se anunció la formación de un llamado Comité de Expertos para la Evaluación de los Sistemas de Producción de Manuscritos Múltiples.

El Comité visitó en su taller a un ciudadano que dijo llamarse Juan Gutenberg. Los expertos escudriñaron todos los rincones de su rudimentario taller y escucharon admirados al fantasioso artesano que les explicó y demostró el funcionamiento de la singular herramienta. El grupo de trabajo continuó sus pesquisas, recabó las opiniones de otros expertos, celebró numerosas reuniones y tras muchas discusiones, redactó un informe que fue elevado al inquieto gobernador.

La máquina, decían los expertos, es un artilugio admirable que demuestra el ingenio de su creador. Su aplicación, sin embargo, sería muy limitada, por lo que coincidían en recomendar que el gobierno no invirtiera dinero en su desarrollo y expansión. El concilio de sabios desaconsejaba finalmente la realización de futuras investigaciones sobre las ocurrencias del ciudadano Gutenberg por tres razones fundamentales:

- Primera, porque si tal artefacto entraba en funcionamiento, se produciría una gran masa de cesantes entre los miles de monjes y escribas que se ganaban el cielo copiando manuscritos a mano.

- Segunda, porque no era previsible una gran demanda social para la producción de copias de manuscritos.

- Y tercera, porque a largo plazo, el mercado de libros impresos era dudosamente rentable, dadas las altas tasas de analfabetismo existentes.

Gutenberg terminó por vender aquellos "malditos talleres".

\section{Lo nuevo y lo permanente}

La lección, decía Giner, es clara: "Cinco siglos después, las cosas apenas han cambiado: el advenimiento de los primeros computadores despertó parecidas reacciones. Hubo entonces quien, tras un estudio concienzudo de aquellos gigantescos cerebros electrónicos, pronosticó que la humanidad estaría suficientemente abastecida con tan sólo cuatro ejemplares de tales equipos. ¿Quién podía entonces imaginar una flota mundial de decenas de millones de computadores a la vista de aquel primer artefacto construido en 1946, que medía 27 metros de largo , pesaba 30 toneladas, necesitaba 18 mil tubos y consumía 150 kilowatios para efectuar 500 multiplicaciones por segundo, hazaña que suponía reemplazar el trabajo simultáneo de 200 personas?".

El desafío planteado por la revolución tecnológica, sigue en pie. Encararlo es, por cierto, una tarea que compete a toda la sociedad, a todas las profesiones y oficios. Pero resulta particularmente compleja y trascendente para el periodismo y las comunicaciones ya que, según un grupo de expertos convocado por The Economist, junto con el tercer milenio se inició una nueva era Gutenberg: "En 2001, cinco y medio siglos después de la primera Biblia de Gutenberg, se inventaron nuevamente los 'tipos móviles"”. Se refiere la revista británica, al matrimonio formado por Ben y Mena Trott, que dio comienzo a la nueva revolución. Dollarshort, un diario de vida on-line, que recogía "tontas pequeñas anécdotas de niñez" de Mena, tuvo un éxito inesperado. Lo siguiente fue "un paso natural y lógico": construir una herramienta que hiciera más fácil la confección del blog por cualquier persona. El matrimonio Trott denominó "Tipo Móvil" la nueva herramienta, la misma que permite actualmente que florezcan los blogs por millones. 
Gutenberg hizo posible la difusión de textos -informativos o no- a públicos múltiples pero anónimos. Esa fue la característica de la primera revolución de las comunicaciones. La segunda, que está comenzando y que aun no define por completo sus características, agrega el elemento personal y participativo.

Esto no es novedad. En junio de 1974, en una reunión de expertos celebrada en Palo Alto, California, Wilbur Schramm sostuvo que "nos encontramos en la primera década de lo que los futuros historiadores podrán describir como la edad de la información" "3. Hoy día, cualquier persona con un mínimo de habilidades tecnológicas, un computador y una conexión a Internet puede llegar a un público más vasto que el que escuchó al mítico Luis Hernández Parker en toda su existencia o leyó a cualquiera de los grandes maestros del periodismo mundial de todos los tiempos.

Según el citado informe de The Economist ${ }^{4}$, en los primeros meses de 2006, "cada segundo, cada día, se crea un nuevo blog", liberando a sus creadores de la necesidad de recurrir al pesado (y costoso) equipamiento que se requirió hasta ahora para difundir ideas, informaciones y comentarios, la finalidad tradicional de los medios.

Desde su perspectiva como formador de futuros profesionales de la información, el profesor Giner sostuvo hace años ${ }^{5}$, cuando todavía no entraba el blog en escena, que "las nuevas tecnologías tienden a democratizar el acceso a los mensajes informativos. Cuando estas tecnologías estén al alcance de cualquier empresa -y esa tendencia es irreversible- lo distintivo del trabajo periodístico ya no será la ventaja técnica sino la calidad del servicio profesional que se preste. Por eso el mayor capital de las empresas informativas de mañana serán sus hombres: editores y periodistas que con su competencia profesional dan el auténtico 'valor añadido' que hace atractivo a un servicio periodístico".

La novedad de Internet -que no exige una gran inversión- es que posibilita que cualquiera pueda tener su propia plataforma para pararse sobre ella y le hable al resto de la humanidad. "La red, señala el periodista chileno Enrique Mujica, ha solucionado dos problemas esenciales: las barreras para entrar al negocio, es decir, la producción y el soporte (tener un sitio web, o sea un medio para comunicarse, es más barato que comprar un jeans); y la distribución (dicen que el 70\% de los lectores del sitio web de The New York Times nunca han tenido un diario impreso en sus manos)".

Solucionados estos dos problemas que parecían los más difíciles de sortear, estamos descubriendo que hay una nueva gran incógnita, hasta ahora no prevista: el desafío ético.

Por Internet se puede mentir, robar, plagiar y falsificar documentos, textos, voces, fotografías y animaciones sin dejar huellas. No hay ley que garantice la autenticidad de lo que encuentran los internautas en su navegación por los espacios virtuales. Solo queda reiterar que la mejor salvaguardia de la buena fe de los usuarios es una firme conciencia ética. Ello, para muchos lectores habituales de periódicos o auditores de radio y tele-espectadores, puede parecer insuficiente.

\section{No todo es verdad...}

Se trata, principalmente, del tema de la verdad, la confianza y, a fin de cuentas, de la credibilidad. Yo leo el periódico, escucho la radio o sigo las noticias en la televisión porque quiero estar informado, pero lo hago en determinado diario, radio o canal porque tengo confianza en quienes me prestan ese servicio. Pese a todas las denuncias sobre manipulación y distorsión, es evidente que, en este tema, todos estamos

\footnotetext{
${ }^{3}$ Diario El Mercurio. Chile. 3 de julio de 1974.

${ }^{4}$ Revista The Economist. Edición del 22 al 28 de abril de 2006: "A special report on new media".

${ }^{5}$ Diario La Nación. Argentina. 27 de agosto de 1986
} 
dispuestos a transar: no hay medios perfectos, pero confiamos en ser capaces de evitar la manipulación burda. A pesar de que cuando se les consulta, los públicos son muy críticos al respecto, en definitiva se muestran razonablemente satisfechos con lo que obtienen de los medios.

Lo que ofrecen, en cambio, los blogs o las páginas personales, hechas a veces por periodistas pero generalmente producidos por alguien que da referencias muy escuetas acerca de su profesión, capacitación o adhesión ideológica o religiosa, es puro misterio. Lo que leamos puede ser verdad. Pero también puede no serlo: a) por error, lo que ocurre también en los medios tradicionales, b) por uso sin mala intención de datos equivocados o, c) por error deliberado y mala intención.

Como fuere, el resultado es el mismo.

Cuando pasó el primer impacto de la caída de las torres gemelas en Nueva York, la red recogió decenas de versiones inconfirmadas: que nunca hubo ningún avión que se estrellara contra el Pentágono; que en la nube de humo que se cernía sobre Manhattan se veía claramente el rostro del demonio; que entre los restos de una de las torres se había encontrado una cámara fotográfica en cuyo interior se había salvado una imagen de un turista y, detrás suyo se veía a uno de los aviones a punto de estrellarse...

Algunas eran -casi- una broma. Pero otras, como relatos de cifras no reveladas, de heridas atroces y de pérdidas de archivos y documentos irrecuperables, solo sirvieron para alimentar temores y especialmente la ola de xenofobia que invadió a los Estados Unidos. Cinco años después, la historia de un eventual derrumbe provocado por el gobierno federal mediante cargas explosivas todavía tiene seguidores. La reiteró en septiembre de 2006 el Presidente venezolano Hugo Chávez.

Nunca fue fácil la educación medial. Leer el diario no es sólo cuestión de juntar letras, como no es suficiente reunir imágenes o sonidos para entender lo que se recibe de la radio o de la TV. Pero en este mundo nuevo de las redes multimediales y de la interactividad, el esfuerzo es, sin duda, mayor que nunca y por lo tanto la formación del usuario crítico de la red es un desafío mayor.

\section{Los grandes cambios}

Este escenario plantea una serie de interrogantes adicionales para la enseñanza y el ejercicio del periodismo. Pero, para abordarlas, conviene empezar por un repaso de la situación. En Chile, en los años posteriores a la recuperación democrática, se han registrado novedades importantes. Entre ellas hay que considerar que:

a) el panorama periodístico, que por una década después del final del régimen militar permaneció muy estático, sufrió un vuelco importante alrededor del año 2000. Ello se debió, probablemente, a una toma de conciencia de que efectivamente había ámbitos más amplios de libertad, a la crítica creciente acerca del comportamiento de periodistas y medios durante y después de la dictadura, al cambio que se produce en la sociedad chilena luego de la detención de Augusto Pinochet en Londres y, adicionalmente, a la promulgación de la Ley de Prensa.

b) en el mismo lapso se avanzó considerablemente en la incorporación de Chile a la Sociedad de la Información, pasando entre 1990 y 2000 de un acceso muy limitado a las redes informáticas a un desarrollo creciente y que hoy se puede considerar masivo. $\mathrm{Su}$ significado no se reduce, sin embargo, a la accesibilidad, sino que pasa por las nuevas formas de informarse y de intercambio, que han entrado en una etapa todavía difícil de medir y menos de analizar con la aparición de los blogs.

c) la televisión, que hasta 1990 sufrió severas restricciones, fue liberándose de ataduras, tanto por la incorporación de canales privados como por la gran expansión del cable. El cambio tecnológico en la televisión hace pertinente cuestionar, por lo menos 
en este ámbito, la tradicional separación entre información y opinión, debido a la mejor calidad de las imágenes, la "portatibilidad" de los equipos y la desacralización de ciertas labores periodísticas o de lectores de noticias. Nuevos equipos -por ejemplo: cámaras muy pequeñas- agregaron un elemento nuevo al trabajo periodístico en TV como el uso (y abuso) de cámaras escondidas en reportajes de denuncia.

d) los medios escritos también han experimentado cambios importantes, incluyendo el impacto del desarrollo tecnológico. Los años 90 marcaron el fin de las revistas "de oposición", la última de las cuales fue la revista Hoy, que desapareció justamente cuando Pinochet era detenido. Igual suerte corrieron los diarios disidentes anteriores al año 90 (Fortín Mapocho y La Época) y El Metropolitano. Posteriormente se agregó el Diario Siete a la lista, tras breve existencia. El esfuerzo de renovación más significativo de los medios escritos ha sido el de Las Ultimas Noticias, que cambió profundamente su esquema y ha basado su éxito de ventas principalmente en comentar la televisión y que se ayuda, para conocer las preferencias del público, en el número de visitantes que tiene cada una de sus notas periodísticas puestas en Internet.

e) las escuelas de Periodismo, reducidas a su mínima expresión después del golpe de 1973, existen hoy en 40 universidades chilenas, las cuales llegaron a tener hasta 64 carreras o programas de periodismo. En una universidad del Consejo de Rectores los estudiantes de Pedagogía pueden optar por Periodismo en el último año mientras sus compañeros se titulan de profesores de Castellano. Una estimación dada a conocer en el diario La Nación en el año 2005 indica que había 9 mil 62 periodistas en Chile, de los cuales 7 mil 147 eran menores de 35 años.

En síntesis: traspasada la mitad de la primera década de este siglo, los medios en Chile se enfrentan a situaciones inéditas.

Hay espacios más amplios de libertad que los que hubo durante muchos años, especialmente desde 1973. Como resultado, el periodismo ha despertado del letargo en que estuvo sumido incluso después del término formal de la dictadura en 1990. Pero, simultáneamente, se ha visto desafiado por una nueva estirpe, los opinólogos, no siempre periodistas, que traspasan sistemáticamente algunos límites tradicionales del ejercicio informativo, como la vida privada, pero que gozan de una generalmente efímera popularidad. También se registra la aparición de nuevos equipos de registro y envío de información, que hacen posible un mejor trabajo en terreno (piénsese solamente en la cobertura del terremoto de Iquique o en la tragedia de Antuco) pero que -simultáneamente- han generado amenaza insospechadas, como las entrevistas emboscadas realizadas con cámaras escondidas o los casos de invención, plagio y alteración de imágenes denunciados en Estados Unidos.

\section{¿Nuevo o viejo periodismo?}

Lo anterior no ha mejorado la percepción de los chilenos acerca de los periodistas y los medios. Una encuesta del Consejo Nacional de Televisión (2005) mostró que a la hora de las noticias se produce la mayor concentración de público. Pero esos mismos televidentes critican con dureza la calidad de la información, la que encuentran sesgada, cargada a lo policial y a lo trágico. A pesar de estas críticas, confían más en la información que ven en sus pantallas que las que reciben por la radio o los diarios.

Este es el escenario medial que ya están enfrentando los egresados de las Escuelas de Periodismo y que, posiblemente con tintas más cargadas aún, recibirá a quienes están actualmente ingresando a ellas y que enfrentarán un campo laboral extremadamente difícil. 
Los cincuenta años del Colegio de Periodistas, fueron ocasión propicia para una autoevaluación, cuyo resultado es de dulce y de agraz. En 2006, entre julio (fecha del aniversario) y septiembre (cuando se cumplieron 20 años del asesinato del periodista José Carrasco), hubo profusión de actos, discursos y despliegues de recuerdos. Pero no hubo consenso a la hora del balance ni de la proyección de lo que espera a la profesión. Menos respecto de los desafíos de la enseñanza.

La primera pregunta es: ¿con qué conocimientos, con qué visión del periodismo queremos que salgan los actuales estudiantes? ¿Qué les estamos diciendo a los estudiantes respecto de la ética en el ejercicio profesional? ¿O la exigencia de un verdadero periodismo de investigación, que va más allá de una denuncia espectacular?

Y sobre todo: ¿qué les estamos diciendo del periodismo como experiencia de vida, como servicio, como responsabilidad frente a la sociedad? ¿Qué significa para estas nuevas generaciones la tradicional exigencia de esforzarse por encontrar la verdad "detrás de cada noticia"?

No es un tema menor. Lo estipula con meridiana claridad el Código de Etica del Colegio de Periodistas de Chile en su primer artículo, en que pone un vigoroso énfasis en los conceptos de verdad y veracidad: "Los periodistas están al servicio de la verdad, los principios democráticos y los derechos humanos. En su quehacer profesional, el periodista se regirá por el principio de la veracidad, entendida como una información responsable de los hechos. El ejercicio del periodismo no propiciará ni dará cabida a discriminaciones ideológicas, religiosas, de clase, raza, sexo, discapacidad, ni de ningún otro tipo, que lleven a la ofensa o menoscabo de personas naturales o jurídicas".

\section{Verdad y derechos de la persona}

El Consejo de Etica de los Medios de Comunicación, uno de los dos instrumentos de autorregulación de Chile (el otro es precisamente el Tribunal de Etica y Disciplina del Colegio de Periodistas), ha insistido constantemente en los mismos conceptos. Desde su primer fallo, en noviembre de 1991, ha analizado numerosas denuncias acerca de eventuales "falsedades". De los primeros cien casos, 37 incidieron en la "veracidad", tema tan recurrente en las denuncias como el del "honor".

A mayor abundamiento, el Consejo, en sus "Pautas Éticas" de 1997, colocó en primer lugar la "búsqueda de la verdad", que sintetiza en seis puntos, el primero de los cuales afirma: "Dentro de las limitaciones de la función informativa, el medio deberá buscar la verdad y practicar la veracidad".

En su perspectiva, probablemente quien mejor ha enfrentado el tema fue el Papa Juan Pablo II: "No se puede escribir o emitir sólo en función del índice de audiencia, a despecho de servicios verdaderamente formativos. Ni tampoco se puede recurrir al derecho indiscriminado de información, sin tener en cuenta los demás derechos de la persona. No hay libertad, incluida la libertad de expresión, que sea absoluta: en efecto, ésta está limitada por el deber de respetar la dignidad y la libertad legítima de los demás. No hay nada, por fascinante que sea, que pueda escribirse, realizarse o emitirse en perjuicio de la verdad. Y no sólo me refiero a la verdad de los hechos, sino también a la verdad del hombre, a la dignidad de la persona humana en todas sus dimensiones".

En su momento, en medio de los ires y venires del Caso Spiniak y la entrevista de Gemita Bueno ${ }^{6}$ señalé mi personal convicción de que, con la cita anterior del Papa, debería haberse cerrado el debate. Así lo sigo creyendo. Pero es una discusión que no va a terminar fácilmente. Algunos juristas siguen haciendo flamear el estandarte de que los

\footnotetext{
${ }^{6}$ Este caso, que conmovió la opinión pública chilena por sus múltiples aristas, fue exhaustivamente analizado en Dossier, la revista de la Facultad de Comunicación y Letras de la Universidad Diego Portales en su primer número, correspondiente al año 2004.
} 
medios y de los periodistas no están obligados a buscar sin desmayo la verdad. Se basan para ello en un famoso pronunciamiento de la Justicia norteamericana.

\section{El hito de Sullivan y The New York Times}

En la década de los 60 del siglo pasado, en medio de las épicas batallas contra la segregación racial, la Corte Suprema de Estados Unidos ya enfrentó esta pregunta tan vieja como el Evangelio: ¿Qué es la verdad? En el caso "The New York Times vs. Sullivan" este tribunal se vio enfrentado a confirmar o no un fallo en que se condenaba al diario por un dato equivocado.

En apoyo de la campaña en favor de los derechos civiles del reverendo Martin Luther King, un grupo de personalidades publicó el 29 de marzo de 1960 una inserción pagada en The New York Times. El texto, a toda página, recordaba algunos hechos y entre ellos, según se supo más tarde, se incluyeron algunos datos erróneos.

Esta situación llevó a L. B. Sullivan, concejal encargado de la policía de Montgomery, capital de Alabama, a querellarse contra el diario por difamación. Su nombre no figuraba en el aviso, pero alegó que se le acusaba indirectamente de "mala conducta grave" y de "acciones y omisiones impropias de su condición de funcionario público". Pedía, por ello, que el diario se retractara de afirmaciones que consideraba falsas y difamatorias.

La demanda, tras pasar por tribunales menores, llegó hasta la Corte Suprema en 1964. El diario fue absuelto. El académico chileno Carlos Peña, en ese momento vicerrector académico de la Universidad Diego Portales ${ }^{7}$, y otros juristas, han sostenido que, a partir de este fallo debe entenderse que la prensa sólo tiene responsabilidad si emite un discurso "con conocimiento de que es falso o con temerario desinterés acerca de si es falso o no" (doctrina de la "real malice").

Posteriormente, como una extensión de este principio, se ha llegado más lejos. Seguidores de esta corriente de pensamiento han legitimado -incluso- la publicación de rumores. El fundamento sería que la Corte Suprema de Estados Unidos estableció que la prensa no tiene "el deber de verificar con cautela las informaciones que en sus páginas difunde". Según el análisis de Carlos Peña, ahora Rector de la Universidad Diego Portales, extremar el cuidado en esta materia puede producir un efecto peor. Escribió que, de acuerdo a lo establecido por la Corte, obligar "al crítico de la conducta oficial a garantizar la verdad de todos los hechos que alega -so pena de una condena- lleva a la censura".

Este choque de visiones podría ser más aparente que real. Los periodistas hemos rechazado desde siempre la censura previa. El tribunal supremo de Estados Unidos, en este punto, reconoce lo que los periodistas sabemos que es obvio: existe una alta posibilidad de cometer errores en un trabajo hecho generalmente en condiciones difíciles, sin tiempo suficiente y, muchas veces, superando obstáculos deliberadamente puestos por quienes son investigados. Lo que exigen los códigos éticos es la obligación de agotar los esfuerzos por verificar la información que está entregando.

Sintomáticamente, en la misma edición de la revista Dossier en que se publica el comentario del profesor Carlos Peña, se incluye un texto de Andy Young ${ }^{8}$ quien dirige al grupo de profesionales dedicados a verificar los datos de los reportajes que se publican en el semanario norteamericano The New Yorker: "La verificación de datos, asegura, ayuda a cruzar la línea, a veces poco clara, entre la realidad y la ficción. Los

\footnotetext{
7 “Privacidad y medios". En Revista Dossier, de la Facultad de Comunicación y Letras de la Universidad Diego Portales. N³. 2006.

8 "Los datos: el proceso de verificación en The New Yorker". En: Revista Dossier, de la Facultad de Comunicación y Letras de la Universidad Diego Portales. N 3. 2006
} 
escándalos recientes de Jayson Blair y Judith Miller en The New York Times y de James Frey, el autor de las memorias A Million Little Pieces -que ahora sabemos que contenían una porción alta de invención- han demostrado la utilidad de la verificación".

No es, por cierto, la única razón, pero esta preocupación por la exactitud de los datos, es también parte del respeto que el medio (y el periodista) debe al lector. A cambio, recibirá su apoyo económico, pero sobre todo, su adhesión, en especial el aprecio por su credibilidad. No siempre, sin embargo, y en Chile ello es notorio, existe tal cuidado.

La pregunta lógica es ¿por qué hemos llegado a esta situación? Hay causas múltiples, pero hay algunas que son más relevantes a la hora de esbozar una conclusión.

Al haberse formado en universidades "rigurosamente vigiladas" e iniciado profesionalmente en un marco de duras y prolongadas restricciones, muchos periodistas de las más nuevas generaciones -incluyendo a quienes ocupan actualmente cargos directivos- perciben la libertad de prensa, más que como un ideal de servicio, como una obsesión. Pese a los años transcurridos desde el final del régimen militar y los consiguientes avances legales, las lecciones mejor aprendidas por estos periodistas fueron las de legislación (fuente de permanentes restricciones contra las cuales se debía combatir sin tregua), más que las de ética. Solo así se puede entender este convencimiento de que los periodistas y los medios no tendrían la obligación de agotar todos los esfuerzos posibles en la búsqueda de la verdad.

\section{Un servicio y tres desafíos}

Sostener que no es necesario este esfuerzo, puede ser una conclusión brillante para la defensa de un periodista procesado, pero ignora algunos aspectos sustanciales de la función del periodismo, entendido su ejercicio como un servicio y un desafío permanentes:

- El servicio se presta a la sociedad, la cual requiere información. Los periodistas - no en forma exclusiva, desde luego- son los encargados de proporcionar dicha información de manera eficiente o, como decía un antiguo texto del Colegio de Periodistas: "de manera leal, veraz y oportuna".

La Declaración de Chapultepec sobre libertad de Prensa, aprobada en 1997 y ratificada por buena parte de los gobiernos latinoamericanos sostiene que "no hay personas ni sociedades libres sin libertad de expresión y de prensa. El ejercicio de ésta no es una concesión de las autoridades; es un derecho inalienable del pueblo".

- El desafío no es uno solo, sino varios.

El primero es que esta búsqueda de la verdad exige empeñarse con constancia, sin desmayo, con plena conciencia de que se deben satisfacer algunas exigencias básicas. En un texto clásico ("Credo del Periodista"), Walter Williams, fundador de la Escuela de Periodismo de Missouri plantea algo esencial: "El periodista solo debe escribir aquello que con profunda convicción considera ser la verdad".

El segundo desafío nos señala que, además de la verdad, el periodista debe tener y mantener el respeto por la dignidad de las personas. "Nadie debe escribir como periodista lo que no diría como caballero", propone el mismo Walter Williams.

En tercer lugar, un desafío permanente es la obligación de realizar siempre, de manera obligatoria un chequeo básico de los datos, corroborar los antecedentes, no quedarse con una sola fuente, respetar los compromisos con la fuente cuando pide reserva de su nombre, por ejemplo, sin caer en el abuso de las "fuentes cercanas a", que ha hecho una caricatura de un principio respetable y en algunos casos necesario. 
Pero el mayor desafío, anticipado ya a comienzos del siglo pasado por los fundadores de la revista Time, que ahora se ha hecho más urgente que nunca, es el de contribuir a que las audiencias puedan entender cabalmente los procesos informativos.

\section{Lo esencial se mantiene}

Vivimos en medio de una permanente avalancha informativa. Ya era tal en la década de 1920 cuando Britton Hadden y Henry Luce dieron forma a la revista Time que describieron como un "weekly newsmagazine". Lo es en proporción gigantesca hoy día, luego que se han incorporado a la parafernalia informativa la radio, la televisión y finalmente el Internet, transportado a nuestro computador personal vía satélite y con conexión en banda ancha o inalámbrica.

En menos de un siglo el periodismo parece haber cambiado radicalmente. Las nuevas tecnologías no solo han permitido la incorporación de nuevos medios, sino que han revolucionado los métodos de trabajo de los periodistas, la recopilación de información, que es la primera tarea, y también el procesamiento y sobre todo la entrega noticiosa. La revista Time, desde luego, ya no es la misma.

Pese a ello, algunas premisas fundamentales siguen en pie.

La función informativa sigue siendo la esencia del periodismo. No es la única y por ello tradicionalmente se ha hablado en Chile de tres géneros básicos: información, opinión e interpretación. Este último género, el de las explicaciones, es, sin duda, el que mejor responde a la abundancia actual de información y a la imposibilidad de las audiencias de hacer un permanente seguimiento del desarrollo de las noticias.

En la recopilación de la información, no hay otra posibilidad que las tres más tradicionales: hacer entrevistas, utilizar documentación y describir lo que el periodista ve, escucha o percibe con sus sentidos. Esto tampoco ha cambiado. Pero se ha hecho más exigente debido a las posibilidades que ofrecen los nuevos recursos tecnológicos. El uso de la grabadora permitió que muchos periodistas se olvidaran de lo que fue una función fundamental en el pasado y que sigue siendo indispensable: la descripción de los personajes y los escenarios y las situaciones en que se desenvuelven. El computador nos ha entregado valiosas herramientas que ayudan a un mejor periodismo, pero cuyo mal uso puede pervertir la función básica del informador y hacer que olvide su responsabilidad con la verdad... o el respeto a la dignidad de las personas.

Hay programas que permiten manipular imágenes sin dejar huellas. Hay maneras de robar información desde lugares distantes.

"Sin moverse de su escritorio", Jayson Blair, periodista de The New York Times, fabricó reportajes sobre la base de material ajeno, inventó entrevistas, recicló datos e hizo descripciones basándose en las imágenes que podía revisar sin tener que ir al sitio del suceso.

La dolorosa lección que aprendió el periódico en este caso es que nadie está libre de tentaciones. Pero esto no es nuevo. Lo nuevo es la facilidad con que se pueden cometer estos excesos. Sigue siendo una exigencia básica, en consecuencia, esa rara mezcla de vocación de servicio, honestidad y audacia que ha caracterizado a los grandes periodistas de la historia, desde Henry Morton Stanley a Tito Mundt y que ha tenido grandes exponentes a lo largo de nuestra historia a partir de fray Camilo Henríquez, un gran reacio a la censura.

Este es el escenario: nuevas posibilidades gracias a los avances tecnológicos y viejos desafíos.

En la actualidad la primera noticia, en la mayoría de los casos, la obtiene el público, especialmente el popular, de la radio y la TV. Por lo tanto, el papel de los diarios, especialmente los matutinos -que son la abrumadora mayoría en Chile- es de 
complementar esas informaciones con nuevos detalles y, cada vez más, con una dosis de opinión, que varía según el nivel socioeconómico de los lectores.

\section{Adaptarse a los nuevos tiempos}

La "farándula", un tipo de periodismo muy discutido, pero de grandes ratings, es la culminación de esta tendencia, ya que su mayor despliegue corresponde a la hora en que los televisores se encienden para las dueñas de casa, entre las cuales el sectores mayoritario corresponde a los segmentos C3 y D. A este público se le entrega, habitualmente, un tipo de información de escasa relevancia, pero sí muy llamativa, porque se refiere a personajes conocidos del propio ámbito de la televisión o del fútbol, que pese a todo sigue siendo en Chile una "pasión de multitudes". La mezcla de datos objetivos, rumores y opinión (sobre todo descalificaciones gruesas) dista de cualquier definición tradicional de periodismo. Pero su costo es mínimo y sus frutos -traducidos en avisaje- generosos.

En el lado "serio" de este universo, un análisis de los periódicos chilenos nos muestra que en muchos se ha optado por mezclar la información con un toque de opinión. Coincidentemente con lo que ocurre en la televisión, ello es especialmente notorio en los diarios "populares", cuyo público objetivo es el segmento C (C1C2C3).

Aunque no todos los directores lo aceptan explícitamente, en numerosos seminarios de capacitación en que hemos participado surge como una verdad evidente que es necesario adaptarse a nuevos tiempos que exigen una revisión de ciertos conceptos tradicionales. La idea de adoptar una gráfica más audaz, con más color, con textos más breves, es la respuesta que en todo el mundo se ha dado a la crisis de circulación. Al mismo tiempo, el mayor esfuerzo apunta a innovar en la construcción de la noticia que se entrega al lector. Aunque la "pirámide invertida" sigue siendo la mejor respuesta para entregar la primera información sobre algún acontecimiento, no cabe duda que a medida que pasa el tiempo y cuando ya han "golpeado" la radio, la TV e Internet, el diario debe proponerse un objetivo distinto: complementar la información, abundar en explicaciones y profundizar lo que -en los medios electrónicos- es necesariamente breve o buscar el ángulo humano, que despoje de su frialdad a una información llena de cifras o datos técnicos.

En esta perspectiva, todo indica que el género interpretativo, como tal, no debería sufrir revisiones profundas. Los cambios que hemos anotado hasta ahora se refieren a la forma de presentación, ya sea la tradicional por escrito -que debe reconocer la irrupción de nuevos conceptos de diseño, derivados de las posibilidades tecnológicas de la impresión y del desafío de medios como la TV y la computación- o en alguno de los nuevos soportes electrónicos. Estos últimos obligan, por ejemplo, a tomar en cuenta que todavía la lectura en pantalla no es fácil para muchos usuarios, especialmente cuando se trata de textos relativamente largos, los que deben dividirse en fragmentos más fáciles de leer o imprimir. Pero, sobre todo, gracias a Internet, hoy día es posible profundizar la información a niveles inimaginados en el soporte tradicional (papel, especialmente), debido a los links con otras paginas y también con los propios archivos del medio.

Esta realidad nos permite asegurar que el interpretativo debe considerarse como el género dominante en el Siglo XXI. La Sociedad de la Información, caracterizada por el fácil y múltiple acceso a las fuentes mismas de la noticia, requiere de una entrega más completa y equilibrada de antecedentes y proyecciones de los hechos noticiosos. Y, sobre todo, la capacidad profesional de interrelacionarlos y explicarlos. 
El Burgués Gentilhombre de Moliére hablaba en prosa sin saberlo. El conocido periodista chileno Tito Mundt se paseó por los géneros periodísticos sin teorizar ni saber con qué género quedarse, pero con la seguridad de quien conoce el oficio:

-La vida de un periodista -escribió en el capítulo cero de sus Memorias de un reportero- tiene que ser amena. No se trata de que el autor sea un genio, ni que le haya enmendado la plana a Walter Lippman o a Quentin Reynolds. No. El hecho mismo de buscar noticias en los escenarios más lejanos en los momentos mismos en que pasan cosas, en que la tierra tiembla, arde el fuego y se quema una ciudad, cuando estalla una revolución o comienza una guerra, le da a lo que tenga que contar más tarde un sabor de aventura y de cuadro fantástico.

En verdad, sin nombrarlo por su nombre, Mundt estaba hablando de periodismo interpretativo.

\section{Más práctica que teoría}

El periodismo, como disciplina, se caracteriza porque quienes lo ejercen han optado tradicionalmente por la práctica, sin preguntarse siquiera cuales son las leyes que eventualmente gobernarían su desempeño. Sólo a fines del siglo XIX y comienzos del XX, probablemente como resultado de la creación de las primeras Escuelas de Periodismo, se hizo un esfuerzo por sistematizar los fundamentos de la profesión.

Pero, a pesar de algunos esfuerzos aislados", no se habla de una "Teoría del Periodismo" porque estos aspectos no aparecen integrados en "un esquema o sistema de ideas". Tampoco se han planteado como hipótesis que se pueda comprobar.

La causa es, como ya se dijo, esa percepción profundamente arraigada en los periodistas que, por generaciones, han sentido que lo suyo es el ejercicio práctico. A ello se debe la dificultad de responder, tal como ocurría en Chile a mediados del siglo $\mathrm{XX}$, a la interrogante de si se nace periodista o es posible "hacerse periodista", debate fundamental al momento de la creación de las Escuelas universitarias.

Pero también ha influido en esta falta de profundización el hecho de que, a lo largo del siglo XX, sobre todo en su segunda mitad, se observó un vigoroso desarrollo de la teoría de la comunicación, con lo cual los periodistas se sintieron relevados de la responsabilidad de tener una teoría de respaldo para su actividad.

Más tarde surgió un problema mayor. Llegó a pensarse que los periodistas estaban amenazados de extinción. O podrían ver reducido su papel al de meros recolectores de información, renunciando a su tradicional responsabilidad de seleccionar y jerarquizar las noticias.

En Ser Digital ${ }^{10}$ Nicholas Negroponte, creador del Media Lab del Massachusetts Institute of Technology, sostuvo que "en lugar de leer lo que otros creen que son las noticias y lo que otros justifican como digno del espacio que insume, la digitalización cambiará el modelo económico de la selección de las noticias, hará que el interés personal de cada individuo desempeñe un rol más importante y utilizará incluso información que hoy es descartada en la sala de armado (del diario) por considerársela de escaso interés popular".

Negroponte defendía la idea del Daily Me. En el otro extremo, el coreano OhYeon Ho preconiza OhmyNews. Una vez más, como suele ocurrir, es probable que el camino definitivo en esta materia esté entre ambas posturas. Veamos.

\section{La noticia en el pajar}

\footnotetext{
${ }^{9}$ AGUINAGA, Enrique de. Hacia una Teoría del Periodismo.

${ }^{10}$ NEGROPONTE, Nicholas. Ser Digital. Editorial Atlántida. Buenos. Aires. 1995
} 
Lo primero es aceptar el hecho básico: la avalancha informativa que amenaza con ahogarnos. Varios autores han coincidido en esta apreciación. Entre ellos el especialista norteamericano en Etica, Dr. Rushworth Kidder. En una entrevista realizada aquí en Chile, hace algún tiempo, Kidder, fundador y presidente del Instituto para la Etica Global, fue confrontado por este punto ${ }^{11}$ :

$-¿$ Qué va a ocurrir en el futuro, cuando todo el mundo, gracias a Internet u otro tipo de red, esté conectado y tenga acceso a la información? ¿Quién va a asumir la responsabilidad social de la prensa; el papel que a los periodistas nos gusta destacar de la labor de la prensa?

Su respuesta fue más larga y detallada. Pero se puede resumir en solo dos párrafos:

"El trabajo de un editor, en el futuro, va a ser aun más importante que ahora. El trabajo del editor va a consistir en extraer, a través de todas estas enormes cantidades de información, las dos o tres cosas que él crea que el público debe conocer y lograr que la atención del público se concentre en ellas. Y, luego, las 10 ó 20 informaciones que sería conveniente que conociera; además habrá 40 ó 50 cosas más en las cuales alguna gente estará interesada. El trabajo de los editores será poner en orden todo esto.

"Hay alguien, el proveedor de información, cuya tarea será tratar de convencerlo de que su información es lo más importante del mundo y Ud. tiene que tenerla. Cuando Ud. tenga cuatro mil informaciones, a través de Internet, Ud. va a decir: 'Me rindo. No puedo manejar todo esto'. Entonces Ud. va a recurrir a algún tipo de publicación, electrónica o en papel, lo que sea, que le ponga en orden todo este material y le diga qué es lo importante y qué no lo es tanto".

A la avalancha, se ha agregado ahora otra realidad: la instantaneidad total. En septiembre de 2001, ocurrió lo que Dominique Wolton, sociólogo del Centro Nacional de Investigación Científica de Francia, considera un hecho histórico: "Por primera vez, un incidente bélico tuvo lugar de manera simultánea con la información".

El hecho y la información fueron simultáneos. Millones de personas, en todo el mundo, vieron el 11 de septiembre de 2001 como el segundo avión secuestrado se estrellaba contra la torre sur en Nueva York, en una espectacular demostración de eficiencia de los informadores... y de notable capacidad de "producción" del evento por parte de los terroristas.

En esta etapa del análisis, conviene retomar el tema de los blogs. ¿En qué consisten las propuestas de Nicholas Negroponte y de OhYeon Ho?

\section{El Daily Me (Negroponte)}

La propuesta: "Imagínese un futuro en el cual su agente de interfaz pueda leer todos los telegramas de las agencias noticiosas y todos los diarios, captar todas las estaciones de radio y televisión del mundo y armar un sumario personalizado... ¿Qué tal si un diario estuviese dispuesto a poner todo su plantel de periodistas a sus órdenes, para que le preparen una edición a su medida?..."

El problema: Pese a su atractivo, este Diario Mio (Daily Me), nació con un pecado original: olvidó de que el periodismo no es solo un canalizador de informaciones al servicio de los intereses de cada persona, sino que tiene que ver con la sociedad en su conjunto. No se trata de dar solamente las buenas noticias. También las malas noticias, que seguramente serían excluidas sistemáticamente en una selección personalizada. En ese caso, difícilmente nos enteraríamos de situaciones que exigen nuestra solidaridad o

\footnotetext{
${ }^{11}$ Reflexiones Académicas No 8, Facultad de Ciencias de la Comunicación e Información. U. Diego Portales.
} 
nuestro aporte como catástrofes o las necesidades de las personas que viven en condiciones de marginalidad. Pero también podríamos quedar al margen de informaciones que debemos conocer para tomar decisiones, por ejemplo, como hemos visto muy dramáticamente, denuncias, en cualquier ámbito, desde el político y administrativo hasta el religioso.

Un diario "a la medida" podría ser peor que no tener información, ya que me encerraría en mi torre de marfil, como ocurría en el viejo sistema soviético o en cualquier dictadura de nuevo o viejo cuño, donde no se caen los aviones, no hay accidentes del tránsito y nunca se sabe de una denuncia por corrupción... hasta que es demasiado tarde o los protagonistas ya están muertos o han perdido el favor oficial.

\section{OhmyNews (OhYeon Ho)}

La propuesta. El periódico coreano on-line OhmyNews tiene como lema "Cada ciudadano un reportero". Lo fundó Oh Yeon Ho el 22 de febrero de 2000.

Según resume la Wikipedia, "es el primer periódico de su tipo en el mundo que acepta, edita y publica artículos de sus lectores, en un estilo de reporteo de fuentes abiertas. Cerca del $20 \%$ de su contenido es redactado por un equipo de 55 personas, mientras que la mayoría de las notas son elaboradas por corresponsales free-lance, en su mayoría ciudadanos comunes y corrientes.

El problema. Una vez más se trata de romper la tiranía del periodista que decide, por su cuenta, qué es noticia. Pero no hay garantía de un resultado satisfactorio. Lo dice, sin miramientos, el ya citado autor Julio Orione ${ }^{12}$ : "En verdad, las claves de OhmyNews son dos: 1) la explotación de la buena voluntad de los lectores para hacer un diario con presupuesto mínimo, y 2) la ausencia de respeto por las normas de la ética periodística. Todo lo demás es pura cháchara y lamentable ilusionismo".

Agrega Orione que "muchos académicos y estudiosos de la comunicación y los partidarios de la comunicación 'alternativa' baten palmas por la existencia de este engendro. Claro, en su gran mayoría no son periodistas. Sólo saben de periodismo por lo que han leído y nunca han vivido siguiendo las reglas que impone el periodismo profesional". Cumplir, por ejemplo, con el mandato ético de entregar información en forma "veraz, leal y oportuna".

La lección, hasta ahora, es que, más que nunca, se requiere de profesionales capacitados para entender los grandes fenómenos humanos, sociales y políticos de nuestro tiempo. Porque la sociedad necesita de información y los profesionales que pueden proporcionarla de manera organizada, comprensible, útil, somos precisamente los periodistas.

Esta es la primera enseñanza.

La segunda es que, gracias a los nuevos desarrollos tecnológicos, la tarea del usuario debe ser cada vez más fácil y no más complicada, aunque ello requiera más trabajo por parte del periodista. "Pienso que las personas sólo quieren contenido vital y de la forma más apropiada. Y también cuándo ellos quieran y dónde quieran"13, dijo Jeordan Legon, editor de Yahoo! News en una reciente visita a Chile.

La tercera lección es que, en este mundo intercomunicado, tan lleno de información pero igualmente saturado de chatarra noticiosa, colocada con buena o mala intención, hay alguien que debe ser capaz de seleccionar, cuyo oficio es precisamente ése. Y para ello estamos los periodistas.

Y esta información debe ser confiable, firmemente asentada en valores éticos,

\footnotetext{
12 ORIONE, Julio. Op. Cit. Pág. 127 y ss.

13 "Editor de Yahoo! News da luces sobre los futuros medios on-line". Emol.Com. 18 de octubre de 2006.
} 
con respeto a la verdad, y la dignidad de las personas. Con preocupación por los derechos humanos y el desarrollo democrático.

Esa misión del periodismo, irreemplazable, irrenunciable, no se cumple exclusivamente con buena voluntad. Ni siquiera con una firme vocación de servicio. Requiere de una formación consistente y sólida.

Ese es el desafío para las Escuelas y para quienes enseñamos en ellas. 